\title{
Geomagnetic and geoelectric investigation of mineral rocks at Awo, Osun state, southwest Nigeria
}

\author{
OJO Akintayo O.* \\ Department of Physics, Osun State College of Education, Ilesa, Nigeria \\ *Corresponding authorE-mail: akintayoojo@yahoo.com
}

\begin{abstract}
Integrated geophysical survey was carried out at Awo, Egbedore Local Government, Osun State, Southwest Nigeria to identify the location and depth of formation of different magnetic minerals. Proton Precession Magnetometer (G 856AX) and String R1 resistivity meter were used to obtain magnetic and resistivity data respectively. Sufer10 was used to present magnetic intensity anomaly maps and UBC, MAG3D program (version 4.0) was used to generate 3D inversion of the subsurface magnetic data. The slices of the 3D model at different depths were shown. Partial curve matching and Winresist (version 1.0) were used to treat the apparent resistivity data to generate sounding curves. The apparent resistivities obtained were compared with the published magnetic susceptibilities to identify the magnetic minerals and their locations in the study area. The results of the geophysical methods were in agreement and revealed that rocks at the centre towards the south western region are suspected to be Tantalite and Columbite while the north western region possibly harboured rocks such as Sandstone, Quartz and Calcite. More than fifty percentage of the volume has an intermediate magnetic susceptibility values indicating that the study area is predominantly a pegmatite vein and possibly harbours rocks such as Beryl, Tourmaline and Mica in both disseminated and massive quantities.
\end{abstract}

Keywords: AWO, magnetic minerals, magnetic susceptibility, 3D inversion, electrical conductivity.

\section{Introduction}

The surface of the earth has provided the setting for most of human endeavours throughout the history of civilization, and these activities have been profoundly affected by the largely invisible characteristics of the immediate subsurface. Human development has depended heavily on resources obtained from both near surface (as in construction materials) and from hundreds to thousands of meters deep (as in metalliferous ores and petroleum based products). We also use water from subsurface aquifers for industrial and domestic purposes, we deposit much of our waste within the near subsurface, and build structures that must interface safely with these shallow regions [9].

In relation to these activities, subsurface characteristics of particular interest to earth scientists include the location, distribution and structure of rock types, grain size distribution and material strength, porosity and permeability, to name a few. The earth's inherent complexity can make it difficult or impossible to infer these characteristics from direct observation. Therefore, they often must be inferred from the distribution of more fundamental physical properties such as density, electrical conductivity, acoustic impedance and others. These basic properties can be measured via geophysical surveys that record the earth's response to various types of natural or artificial signals [14], [16].

All geophysical surveys involve energizing the earth and measuring signals which result from the earth's effect upon that energy. Measurements will contain information about the types and distributions of subsurface physical properties. For example, DC resistivity and all electromagnetic methods measure electrical resistivity (or conductivity); all magnetic survey methods measure magnetic susceptibility, gravity method measures density, seismic reflection or refraction measures acoustic wave velocity and density. The survey data, perhaps with some filtering, can sometimes be used to answer the question of interest. Generally, the information is insufficient and more quantitative analysis is required. Surveys are done from all conceivable platforms (ground, vehicle, air, marine, satellite and in boreholes) and results are usually presented as maps, graphs, profiles etc. Raw data may be interpreted directly, significant processing may be applied, and inversion to estimate models of subsurface physical properties distribution may be carried out [13]. Geophysicists have long recognized the need for inverting their data. The data need to be inverted to generate a distribution of the physical property. The state of computing resources a few decades ago meant that even the best inversion algorithms could recover estimates for only a small number of parameters. Consequently, the subsurface was 
modeled as a few layers, or as simple prismatic objects, and parameters were adjusted so that numerically modeled data fit the observations as well as possible. Unfortunately, earth structures are generally much more complicated and hence incorrect conclusions were often drawn [2], [6].

In the intervening years, there have been considerable advances in computing power and in the mathematics of inversion. As a result, more realistic inversions are being carried out and the usefulness of geophysics in solving applied problems is increasing. There is an increasing realization that geophysics, which is the only remote sensing discipline available for subsurface problems, must be an integral part of environmental, engineering and exploration problems. There is also a realization that extracting the information about the subsurface from the geophysical data is not a turnkey operation, and that cost-effective solutions generally involve a team of experts because the quality of images obtained from geophysical inversion depends critically upon other information [16], [26].

Magnetic and resistivity methods have found a wide range of applications in mineral exploration, geophysical and geotechnical work in Nigeria [7], [8], [10], [19], and [22]. Nigeria is heavily endowed with mineral resources. What is most urgently needed is to fully investigate and exploit these minerals and also identify the markets for these products. It is hoped that when these are done, not only will Nigeria's foreign exchange earnings improve but will be able to provide jobs in the oil and gas, and mineral industries for our teeming unemployed citizens.

In this study, an integrated survey involving two most common, cost effective and environmental friendly geophysical methods, Magnetic and Electrical methods has been used to identify the location and depth of formation of different magnetic mineral rocks (such as Tantalite, Columbite, Mica, Tourmaline, Beryl and so on) in the study area.

\section{The study area and its geological settings}

The study area is in Awo town, Egbedore Local Government of Osun State, South West, Nigeria. It is bounded by Latitudes $7.76934^{\circ} \mathrm{N}$ to $7.77090^{\circ} \mathrm{N}$ and Longitudes $4.40431^{\circ} \mathrm{E}$ to $4.40560^{\circ} \mathrm{E}$. It is on a pegmatite vein characterized predominantly by Beryl, Tourmaline, Feldspar, Columbite, Mica, Quartz and Tantalite which were found in grains scattered on the ground surface, larger samples excavated by artisan miners were found around the study area.

The study area lies within the crystalline basement complex of Southwestern Nigeria and to the rest of the west African Craton in the region of late Precambrian to early Proterozoic orogenesis. The basement complex of Southwestern Nigeria predominantly composed of Migmatite and Granitic gnesiss; Quartzite; slightly Migmatised to unmagmatised metasedimentary Schist and metaigneous rocks; Charnockitic; Gabbroic and Diorite; and the members of the older Granite suite mainly Granites, Granodiorites and Syenites. Osun State is composed of the Migmatite-gneiss, Quartzite, Calc-silicate rocks, Biotite-homblende Schist and Amphibahtes. Minor rock types are found within these Gneisses and older Granites [3], [21], [24].

The minor rock types include pegmatite composed of Microcline and Quartz, which are wide spread throughout the crystalline basement complex of Southwestern Nigeria [24]. The pegmatite are however, conspicuously absent from the main area of the slightly Migmatised to unmagmatised para-schists and metaigneous rocks. The pegmatite in the Gneisses may be conformable but they are more commonly cross cutting. The Quartz veins and lenses occur in all the major rock types of the basement complex and they are small varying in thickness from a few millimeters to a meter. They show great irregularities in their form and are seen in places to thin out widen or turn in their course. Dolente dykes are also associated with the Gneisses and older Granites, occurring as tabular, unmetamorphosed bodies cross cutting the foliation in the host rocks and are regarded by [1] as the youngest member of the basement complex. They range in thickness from about a few millimeters to half a meter. They trend northeast to southwest and east-northeast to west-southwest [20]. Expectedly, the study area is underlain mainly by undifferentiated gneiss complex and pegmatite vein (fig. 1).

\section{Theory}

\subsection{Magnetic Method}

The study of the earth's magnetism is the oldest branch of geophysics. It has been known for more than three centuries that the earth behaves as large and somewhat irregular magnet [4]. The theory behind the applied magnetics method can be explained by a magnetic dipole in which the basic elements can be seen in a simple bar magnetic. The bar magnetic consists of two poles (dipolar), a positive north pole and a negative south pole, and these poles always exist as pairs. These two poles produce a magnetic field called the magnetic field intensity $(\mathrm{H})$. If a magnetizable body (e.g., iron or magnetite) is placed in an external magnetic field (e.g., the earth's magnetic field), it will become magnetized and produce a secondary magnetic field, determined by the material's magnetic polarization (M). For low external magnetic 
fields (e.g., the earth's), the degree in which the body is magnetized is determined by its magnetic susceptibility, k, and is defined as

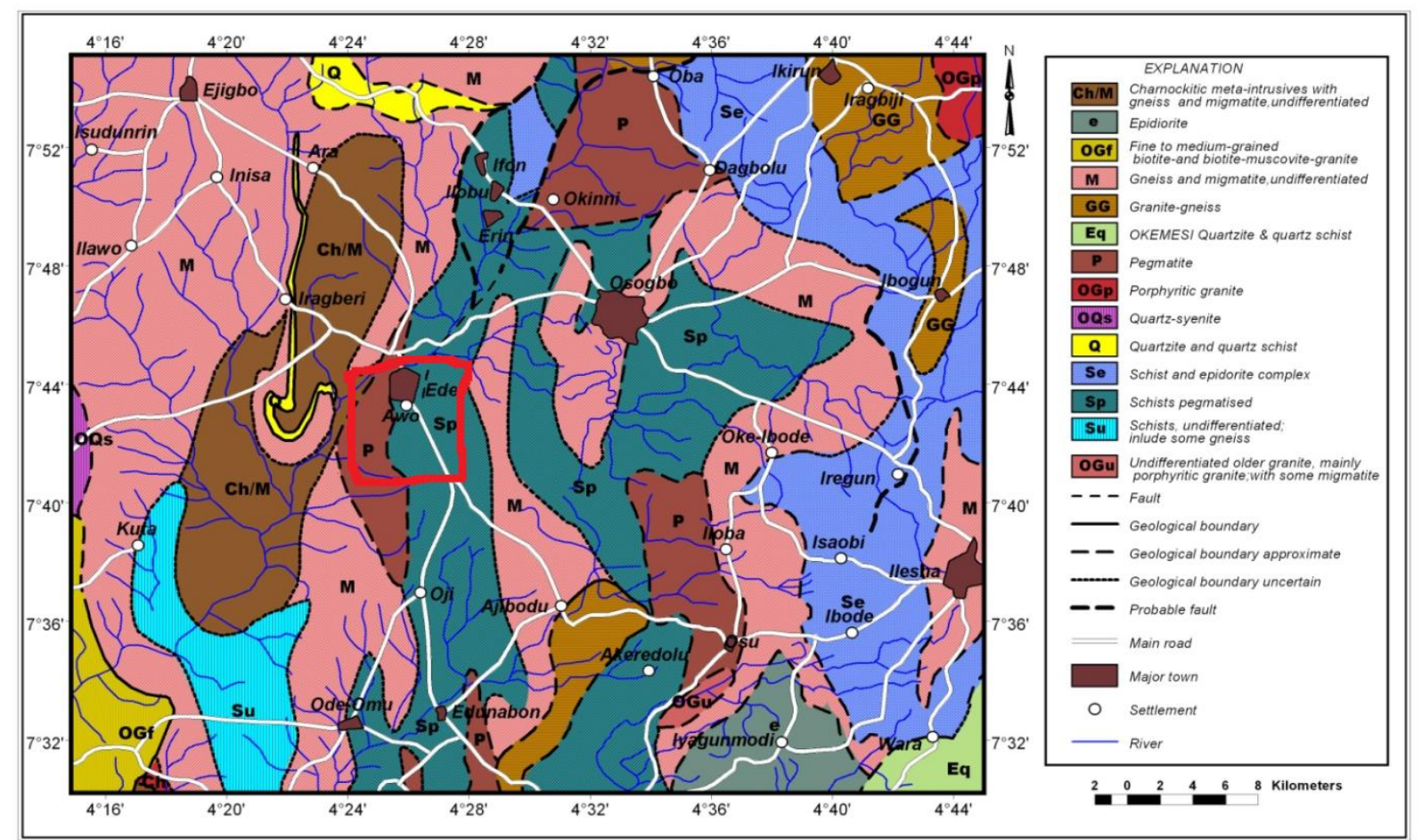

Fig. 1: Geological map of osun state showing the study area, awo town.

$$
M=k H
$$

Magnetic susceptibility is a non-dimensional quantity and is the fundamental physical property used in the magnetic method [8].

The measurement of the total magnetic field, (which includes the external magnetic field and the magnetization) is called the magnetic induction $(\mathrm{B})$ and is written as

$$
B=\mu_{0}(1+k) H
$$

Where $\mu_{0}$, is the magnetic permeability of free space?

The unit of B is tesla, which is generally too large a number for applied magnetics work, so nanoTelsa or gammas $\left(10^{-9}\right.$ teslas) are more commonly used. Also, note that B is a vector quantity and in most magnetic work today, the amplitude of $\mathrm{B}$ is measured and it is called the total magnetic field [8].

\subsection{Inversion}

After acquiring geophysical data set, it is necessary to model or invert the data set so as to obtain the desired subsurface properties images or distribution. The process of estimating geophysical model parameters of a multi-layered and heterogeneous earth model from observed field data is known as inversion. The observed data can be predicted (forward modeling problem), using the laws of physics relating the model parameters to the observed data. Inversion of observed geophysical data involves the mapping of the geophysical data into the model that will, in some defined sense, best satisfy the measured data and our preconception about the given model. The choice of the model parameters is largely dependent on the nature of the geophysical problem to be solved [1].

Data from a geophysical experiment can be generically written as

$$
\begin{aligned}
& F_{j}[m]=d_{j}+n_{j} \\
& j=1, \ldots, N
\end{aligned}
$$

Where $F$ is a forward modeling operator that incorporates details of the survey design and the relevant physical equations, $m$ is a generic symbol for a physical property distribution, and the right hand side represents the observed 
data $d^{o b s}$ which consist of the true data $d$ plus additive noise $n . F$ comes in a variety of forms, but most often it is an integral or differential operator, and the resultant equations must be solved numerically [16].

In general, the inverse problem or inversion in geophysics seeks to find a model that would give a response similar to the actual field data, subject to certain restrictions. The model, whose parameters are the physical quantities or properties that we seek to estimate, is an idealized mathematical representation of the earth. The choice of the model parameters is largely dependent on the nature of the geophysical problem to be solved. The model response is the synthetic data that can be calculated from a relation that defines the model for a given set of model parameters.

In geomagnetic susceptibility imaging, the model parameters are the model susceptibility values with depths and the data are the measured total magnetic field values. The observed and theoretical responses are matched with the use of suitable optimization algorithms which are designed to minimize some measures of the difference between the observed and computed responses. Usually, an initial model (a skilled guess model) is modified in an iterative procedure so that the difference between the model response and the observed data values can be minimized. The model parameters are updated using a linear iterative adjustment procedure [2], [14].

\subsection{Resistivity method}

Conrad Schlumberger first used resistivity method in 1912 [12] and since then electrical resistivity mapping techniques have been employed by many researchers in Nigeria and other parts of the world in identifying and delineating different geo-electric layers. Out of the known geophysical prospecting methods, the electrical methods happen to be the most widely used geophysical method in engineering studies, environmental assessment and hydro-geological investigation. Electrical conductivity (resistivity) is a bulk property of material describing how well that material allows electric currents to flow through it [11]. The electrical conductivity of Earth's materials varies over many orders of magnitude. It depends upon many factors, including: rock type, porosity, connectivity of pores, nature of the fluid (electrolytes), and metallic content of the solid matrix [23].

In resistivity surveying, information about the subsurface distribution of electrical conductivity is obtained by examining how currents flow in the earth [5]. Direct Current (DC) resistivity methods involve injecting a steady state electrical current into the ground and observing the resulting distribution of potentials (voltages) at the surface or within boreholes. Like all geophysical processes, DC surveys can be described in terms of input energy, the earth's physical properties, and signals or data that are measured [17].

The table below shows some minerals electrical conductivity and magnetic susceptibility ranges.

Table 1: Common minerals electrical conductivity and magnetic susceptibility values [27].

\begin{tabular}{ccccc}
\hline Minerals & $\begin{array}{c}\text { Susceptibility } \\
\text { mean, IU }\end{array}$ & Susceptibility range, IU & $\begin{array}{c}\text { Conductivity mean, } \\
\text { Sm }^{-1}\end{array}$ & Conductivity range Sm $^{-1}$ \\
\hline Pyrrhotite & 1.5 & $0.006-1.6$ & 104 & $20.0-1.5 \times 10^{5}$ \\
Ilmenite & 1.9 & $0.3-3.8$ & & $20.0 \times 10^{-2}-1.0 \times 10^{3}$ \\
Magnetite & 6.3 & $5.0 \times 10^{-6}-5.7 \times 10^{3}$ & 3.3 & $1.8 \times 10^{-4}-2.0 \times 10^{5}$ \\
Pyrite & 0.0015 & & 3.3 \\
\hline
\end{tabular}

\section{Materials and methods}

This research focused on the subsurface geological structures based on the qualitative interpretations of both resistivity and magnetic data collected from surveys that were carried on the study area.

\subsection{Magnetic method}

The magnetic survey was designed in such a way that deep insight into the magnetic susceptibility contrast in the study area subsurface was delineated. The data acquisition technique requires measurements of the magnetic intensities at discrete points along traverses regularly distributed within the area of interest. On the study area, ten magnetic traverses were taken with $10 \mathrm{~m}$ spacing in between each traverses and $10 \mathrm{~m}$ stations interval. All traverses were $100 \mathrm{~m}$ long taken in the East - West direction. A total of 110 data points were taken on the study area. A portable geometrics proton precession magnetometer $(\mathrm{G}-856 \mathrm{AX}$ model) with a resolution of $1 \mathrm{nT}$ was used for this investigation and Global Positioning System (GPS) was used to geo referenced each station.

On the research field, repeated readings were made at every thirty minutes at a based station few meters away from the study area to account for the temporal variation in magnetic field. Reoccupation at the base station is to remove the diurnal variation effects of the earth's magnetic field and other sources of external interferences from the data obtained 
[9]. Apart from the diurnal effects, the reductions required for magnetic data are insignificant. The vertical gradient varies from approximately $0.3 \mathrm{nT} / \mathrm{m}$ at the pole to $0.01 \mathrm{nT} / \mathrm{m}$ at the equator. Since the latitude variation is rarely greater than $6 \mathrm{nT} / \mathrm{km}$ [27]. The elevation and latitude corrections are considered negligible.

The values of the total magnetic field, the inclination and the declination at the center of the study area with latitude $07.7690^{\circ} \mathrm{N}$ and longitude $04.4059^{\circ} \mathrm{E}$, were calculated using the National Geophysical Data Center's calculator to have: Declination, Inclination, Ambient field $=-4.769^{\circ},-10.468^{\circ}, 32184 n T$ respectively.

The ground magnetic data collected during the field work were plotted as 3D magnetic contour maps (fig. 2 to 11) using Surfer10 software which shows the regions of high and low magnetic field intensity. The inversion and the observed magnetic data map (fig. 12) were carried out using the UBC MAG3D (version 4). Topography and magnetic data sets were input using the topo.dat and obs.mag format respectively for discredited volume of ground under the data set. In this study, we assume the topography is constant, so we use a constant value for the topography. The recovered 3D model was viewed using MeshTools3D (fig. 13). The variable for the inversion is susceptibility contrast and the recovered model is shown in fig. 14 to 19 at various locations and depths. Inversion constructs 3D model of susceptibility contrast, so interpretation requires an appropriate display for studying the resulting structures. The variation in the susceptibility of the subsurface is displayed in colour which can be matched with the standard susceptibility values of minerals for possible mineral concentration.

\subsection{Resistivity method}

The resistivity survey carried out was also designed to investigate the electrical conductivity of mineral rocks in the study area. The data was acquired using Schlumberger configuration and a total of five Vertical Electrical Soundings were carried out on the study area. All Vertical Electrical Soundings (VES) were $100 \mathrm{~m}$ long, 50m on each side of the referenced point. VES 1 was taken at the west of the study area, VES 2 and 3 were taken at east of the study area, VES 4 was taken across the study area and VES 5 at the South of the Study area. Global Positioning System (GPS) was used to take the longitude and latitude at each referenced points.

The apparent resistivity, $\rho_{a}$ (ohm-m) was plotted against half-electrode spacing, AB/2 (m) on a transparent bilogarithmic (Tracing) paper. The points are joined and we obtain a sounding curve. This enables us to know the number of subsurface layers in each Vertical Electrical Soundings (VES). If a curve has three layers, it can be determined by any of these four types of curves namely H-type $\left(\rho_{1}>\rho_{2}<\rho_{3}\right)$, K-type $\left(\rho_{1}<\rho_{2}>\rho_{3}\right)$, A-type $\left(\rho_{1}<\rho_{2}<\right.$ $\left.\rho_{3}\right)$ or Q-type $\left(\rho_{1}>\rho_{2}>\rho_{3}\right)$. Where there are more than three layers in the curve, we have combination of curves. For example a four - layer curve has a two-letter combination like HA $\left(\rho_{1}>\rho_{2}<\rho_{3}<\rho_{4}\right)$. Knowledge of the type of curve enables the interpreter to know which of the theoretical master curves to be used for curve matching. In this study, all the curves have three subsurface layers and VES 1 and 2 are a - type while VES 3 to 5 are $\mathrm{H}$ - type.

Partial curve matching involves comparing successive portions of the field curve with Schlumberger theoretical (published) master curves of similar shape. The curve is superimposed on and shifted over the master curves until a reasonable match is obtained with one of the master curves or with an interpolated curve. This gives rough estimates of the depths, thicknesses and electrical resistivity of sub surface layers. Winresist 2 was used to generate the sounding curves (fig. 21 to 25 ) and the resulting models generated from the software provide accurate estimates of the depths, thicknesses and electrical resistivity of sub surface layers.

\section{$5 \quad$ Results and discussion}

\subsection{Magnetic survey result}

Two methods were adopted in this study for presenting magnetic data results. These methods are summarized below:

\subsubsection{Contour map:}

This method was used to produce scaled 3D contour maps (fig. 2 to 11). Filling the contour plot helps visualize the magnetic field variations in the study area, this greatly aid interpretation.

\subsubsection{Coloured map:}

Coloured maps are used for plotting raw "total field intensity" data. This is also refers to as 2D observed magnetic data map (fig. 12), it shows the distribution of magnetic anomalies on the study area.

The 3D inversion of the subsurface of the study area (fig. 13) and its slices at various depths and locations are shown in figures $14-19$. An isosurface of the 3D inversion (fig. 20) was also generated which shows the regions with the same magnetic susceptibility values. 

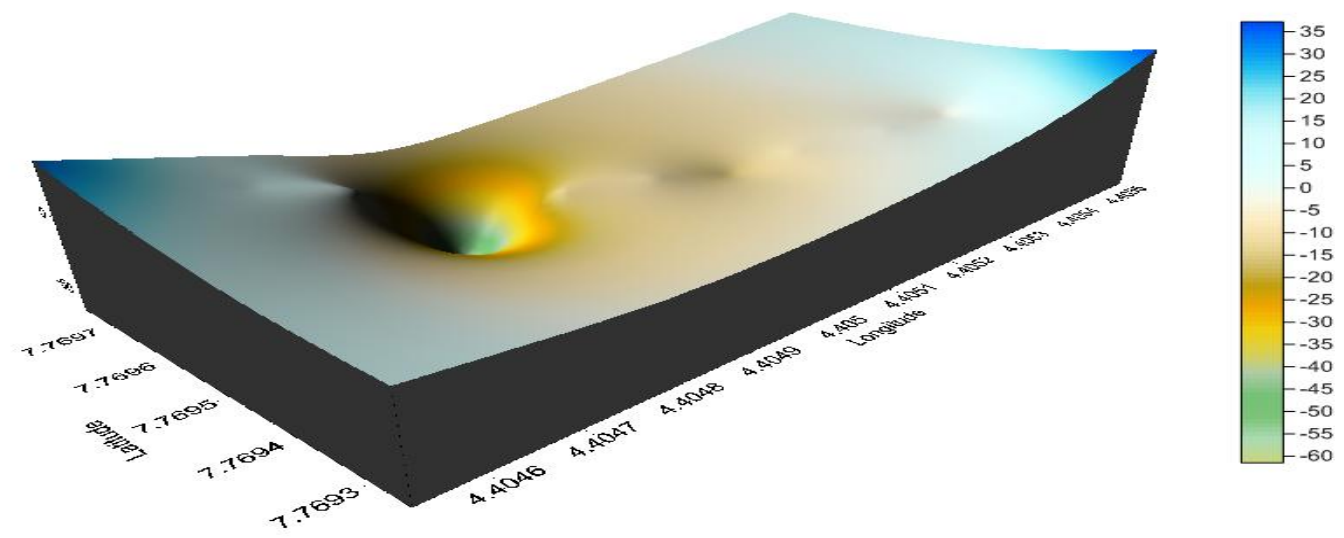

Fig. 2: 3D contour map of profile 1
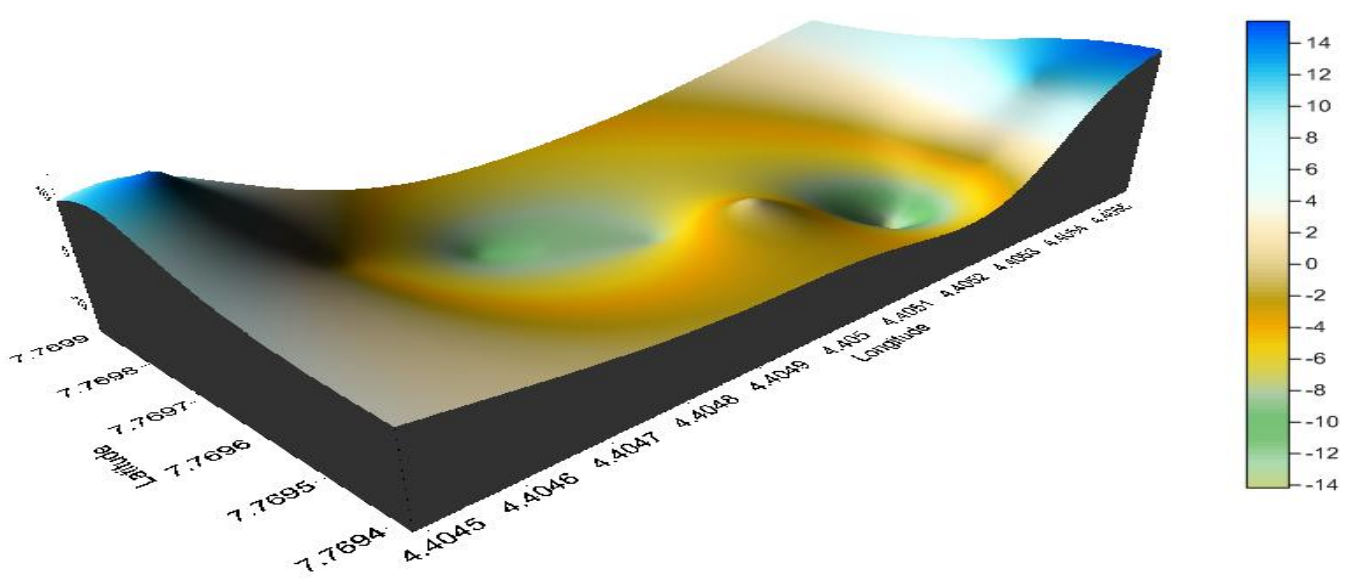

Fig. 3: 3D contour map of profile 2
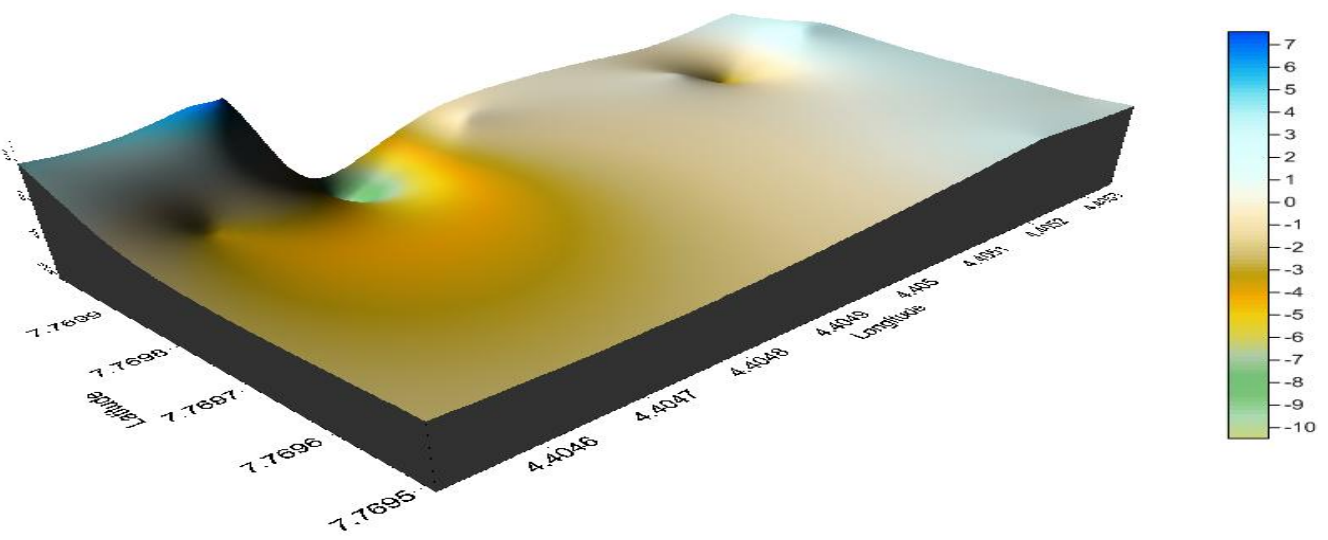

Fig. 4: 3D contour map of profile 3 

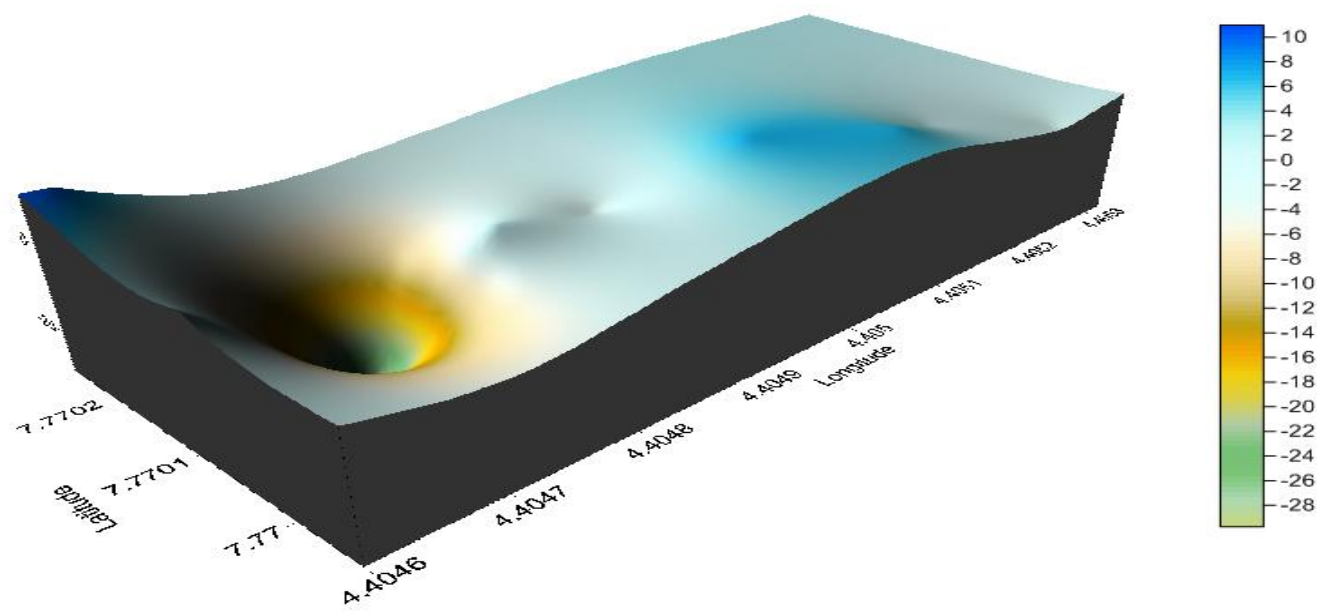

Fig. 5: 3D contour map of profile 4
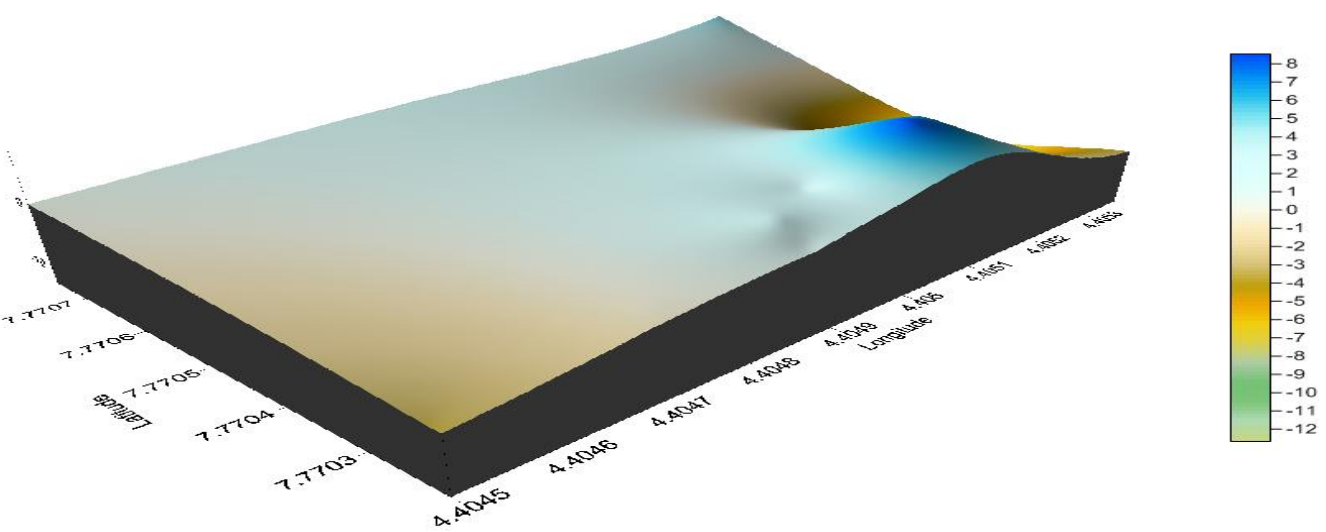

Fig. 6: 3D contour map of profile 5
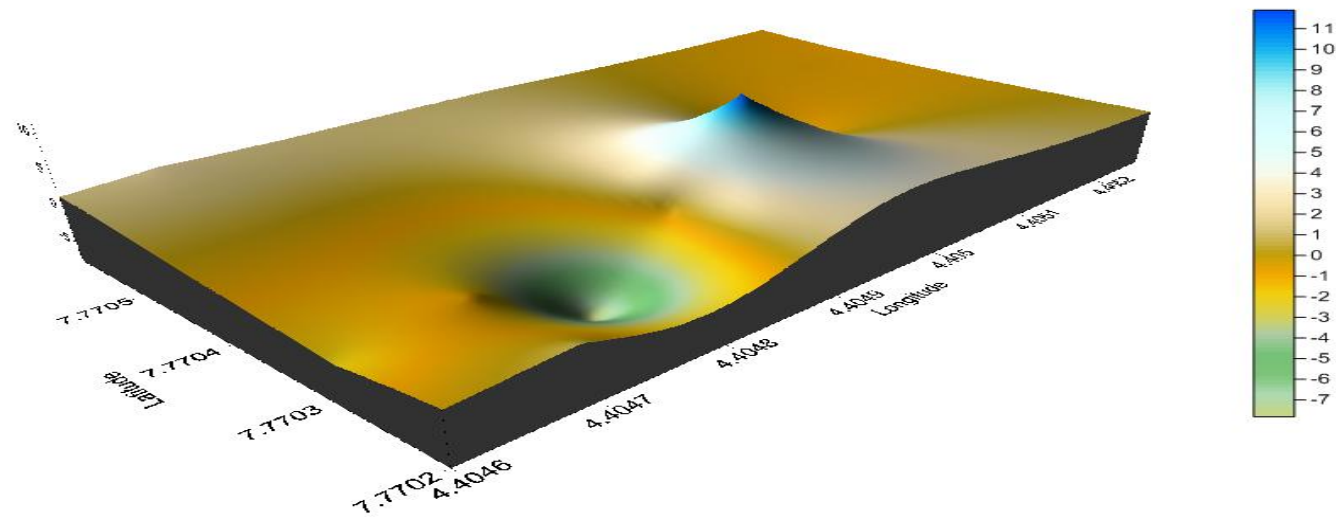

Fig. 7: 3D contour map of profile 6 

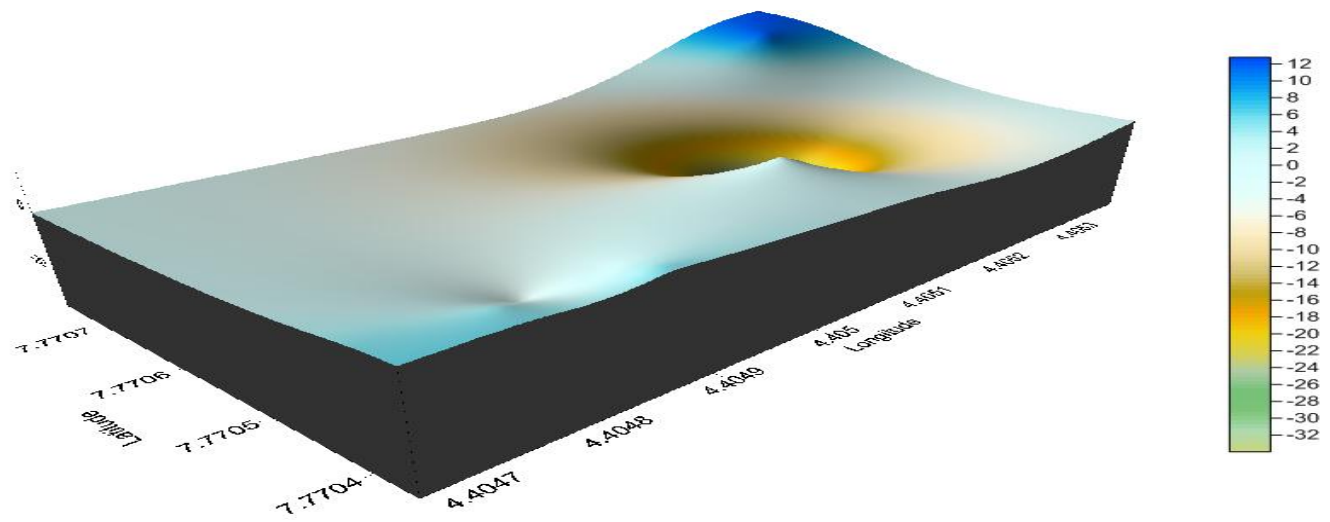

Fig. 8: 3D contour map of profile 7
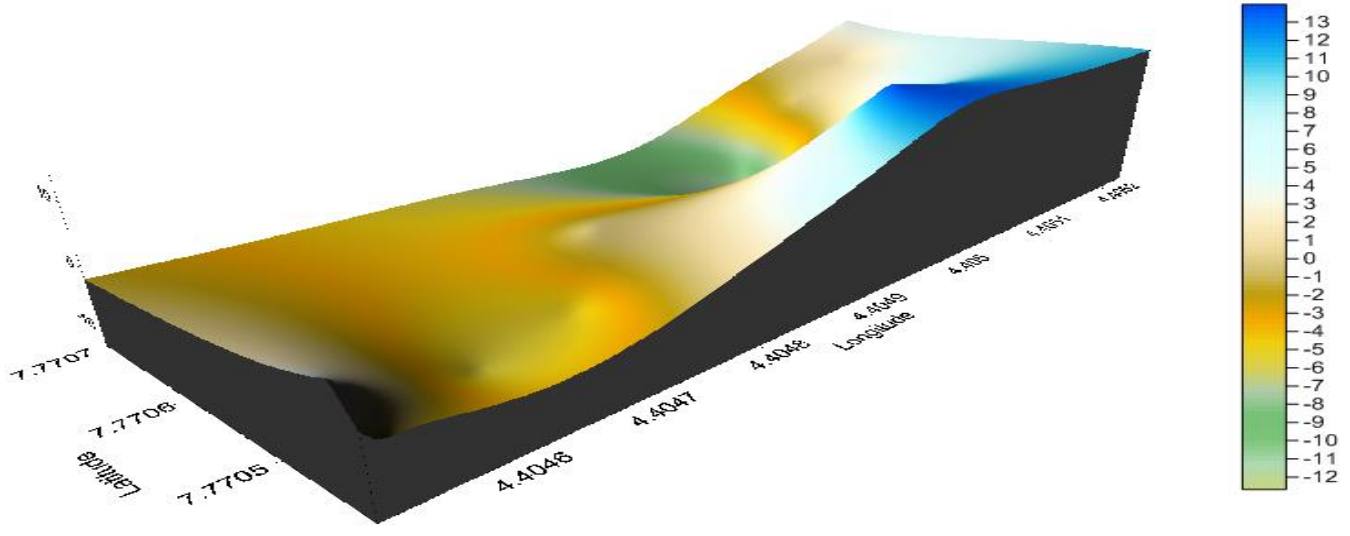

Fig. 9: 3D contour map of profile 8
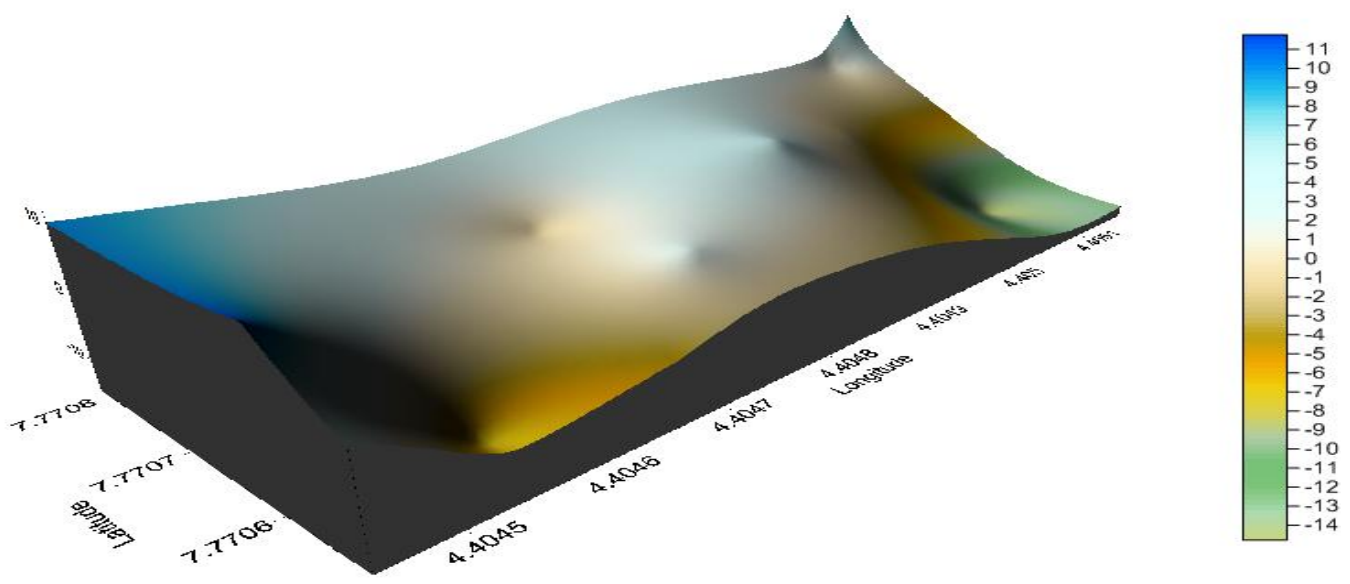

Fig. 10: 3D contour map of profile 9 

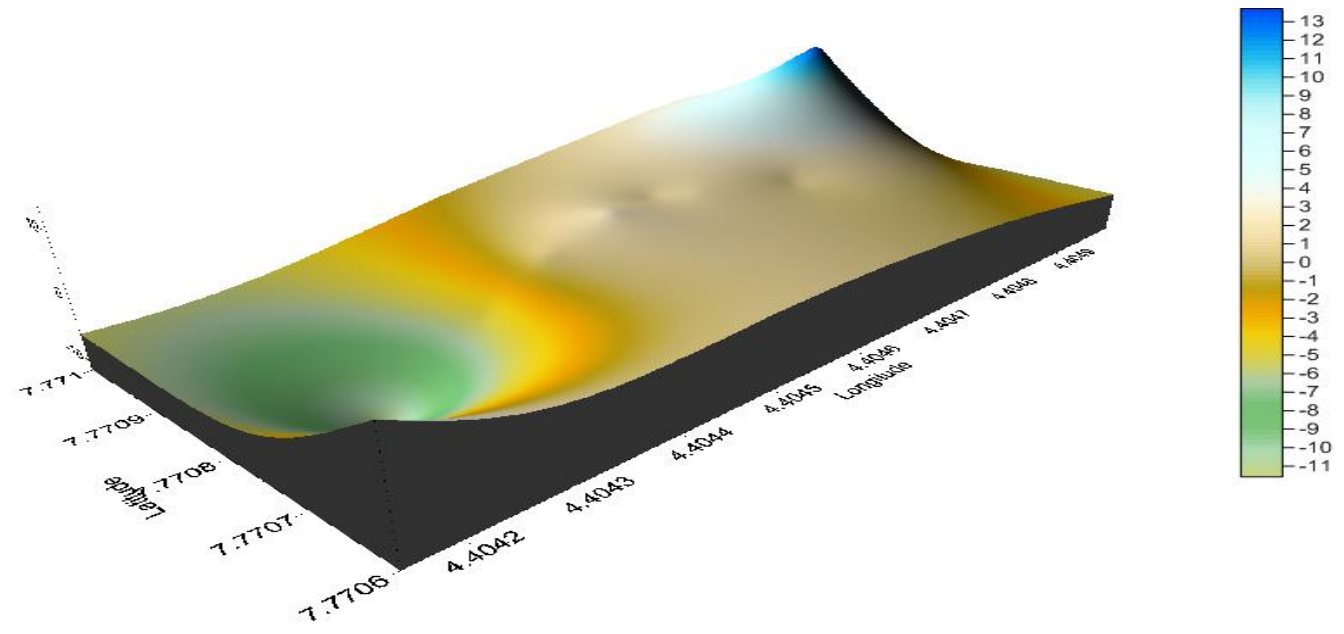

Fig. 11: 3D contour map of profile 10

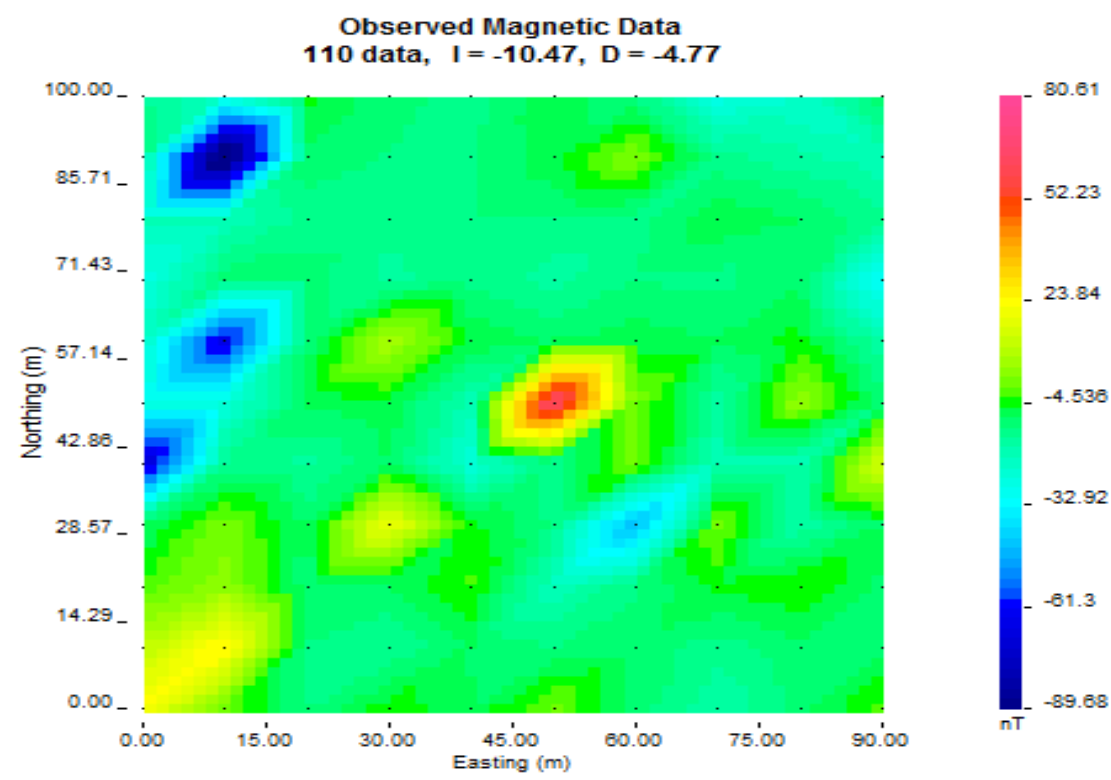

Fig. 12: 2D coloured map showing the magnetic intensity variation of the study area

\subsubsection{D Inversion}

Outcome of inversion is a model of how magnetic susceptibility is distributed in the earth subsurface. The figure below shows the recovered 3D model of magnetic susceptibility generated from the data obtained on the study area. 


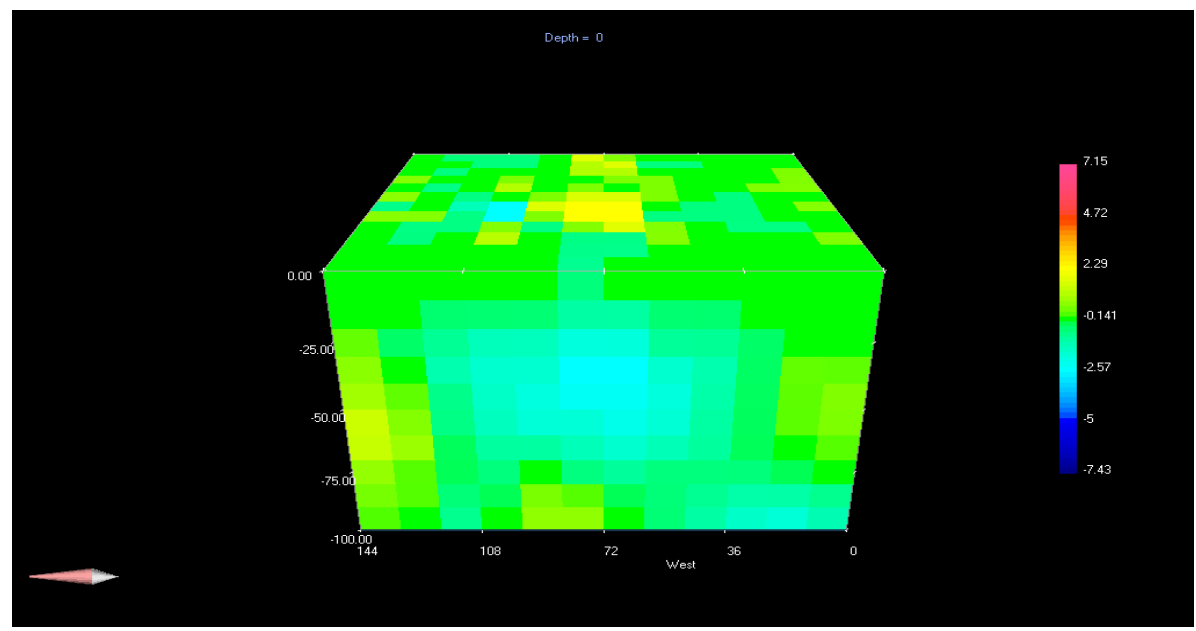

Fig. 13:Recovered 3D inversion / model

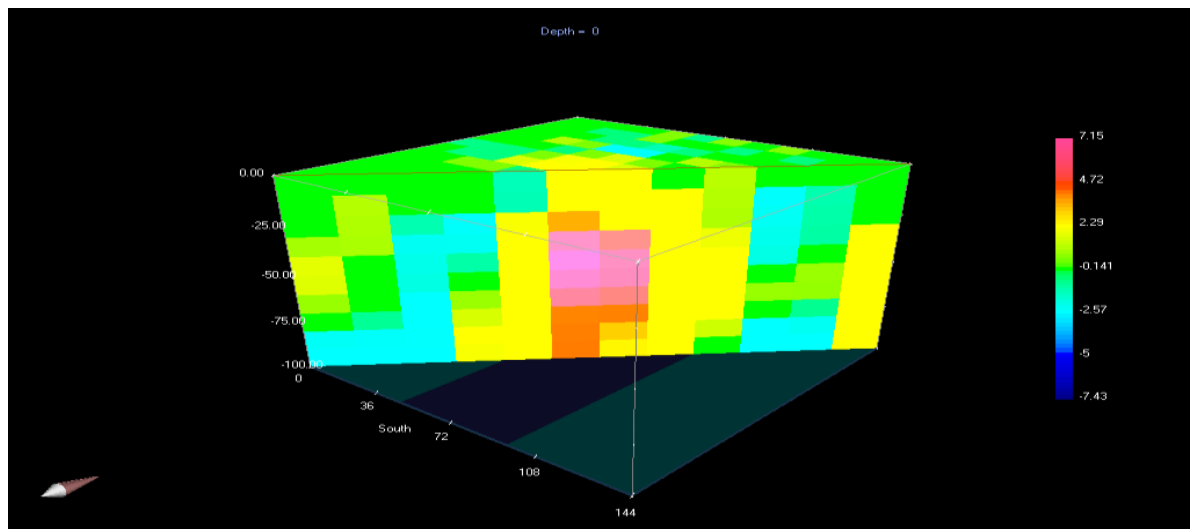

Fig. 14: Diagonal cross section of the model

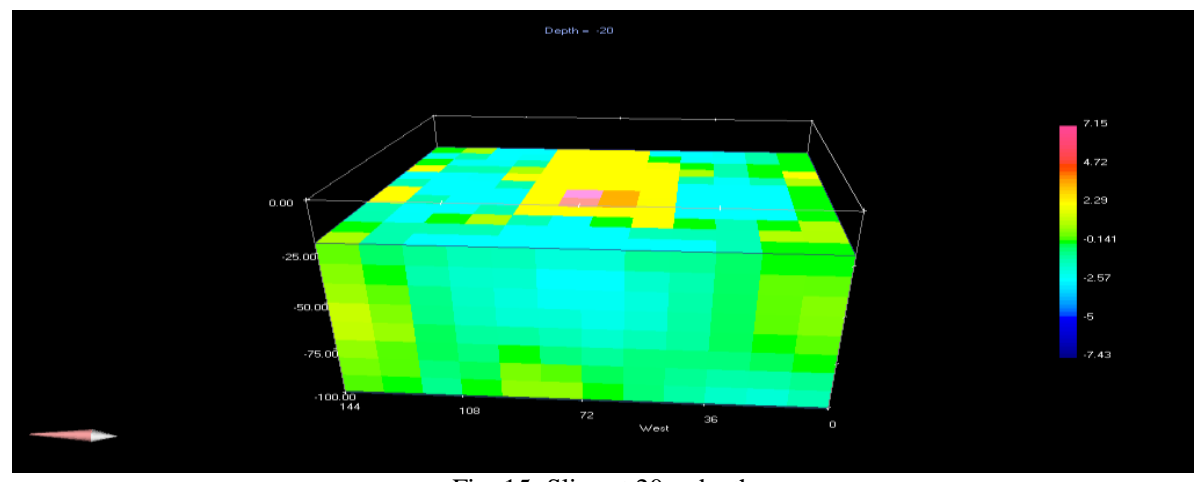

Fig. 15: Slice at 20m depth

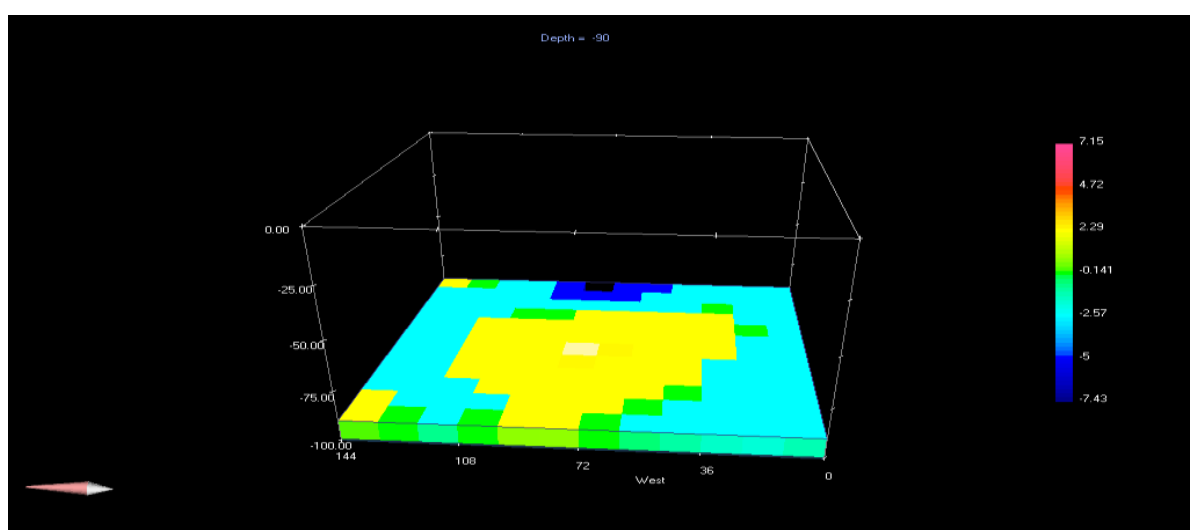


Fig. 16: Slice at 90m depth

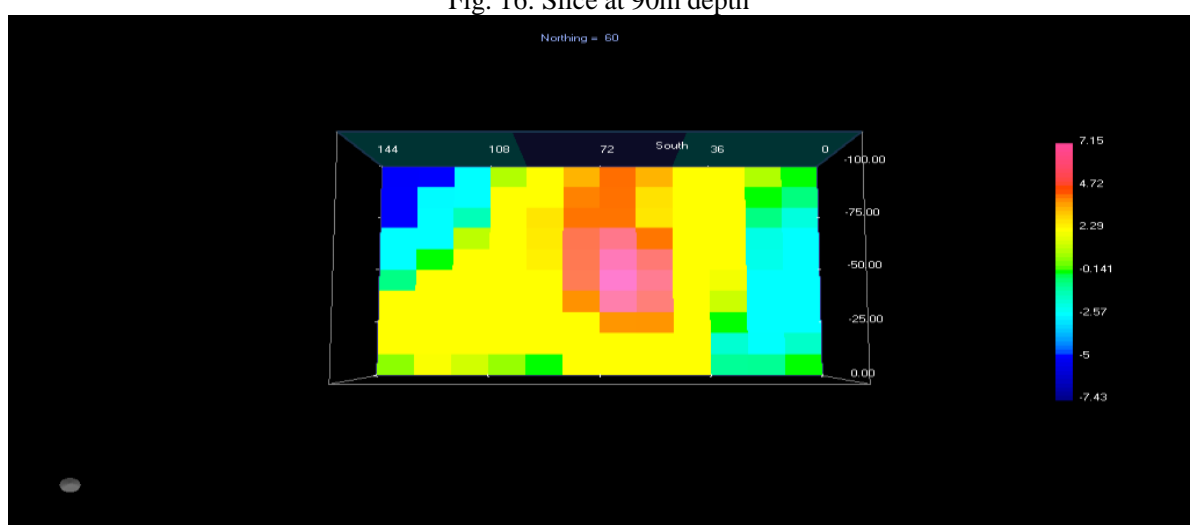

Fig. 17: Slice at 60m North

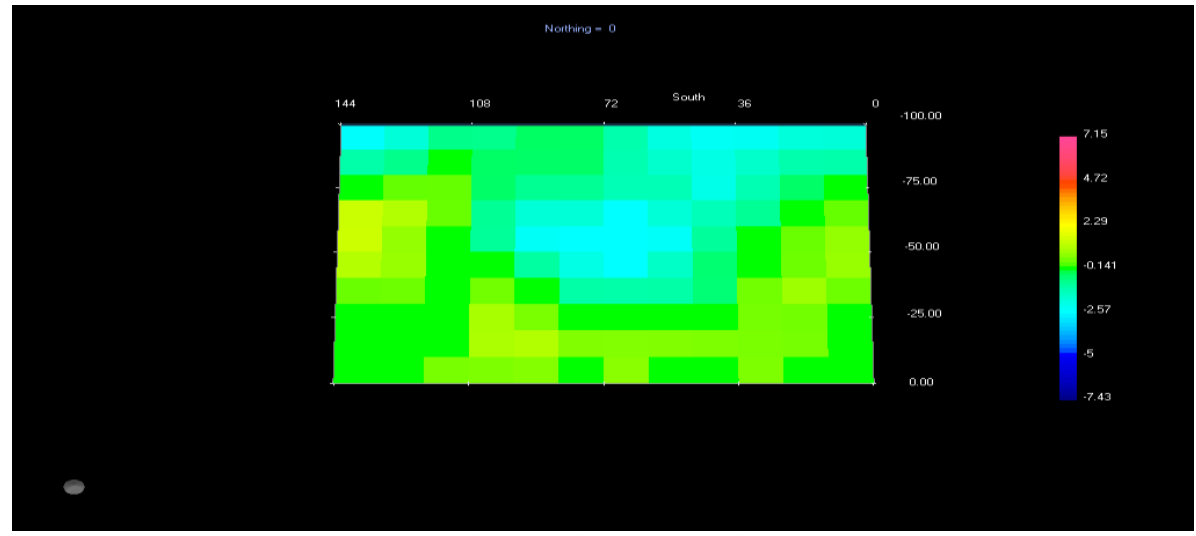

Fig. 18: Slice at 0m North

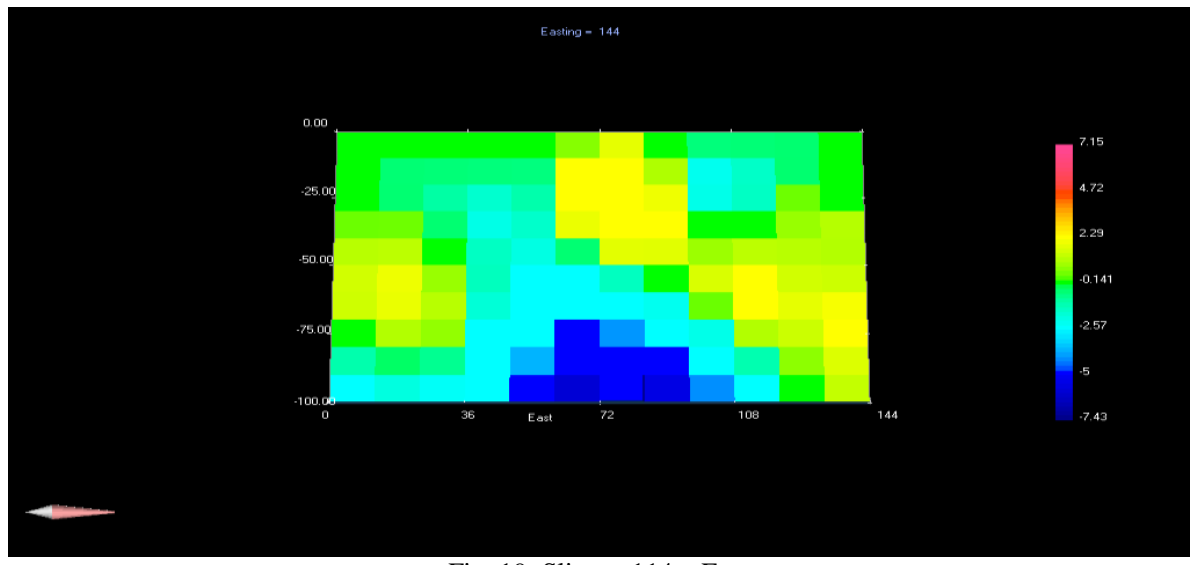

Fig. 19: Slice at 114m East

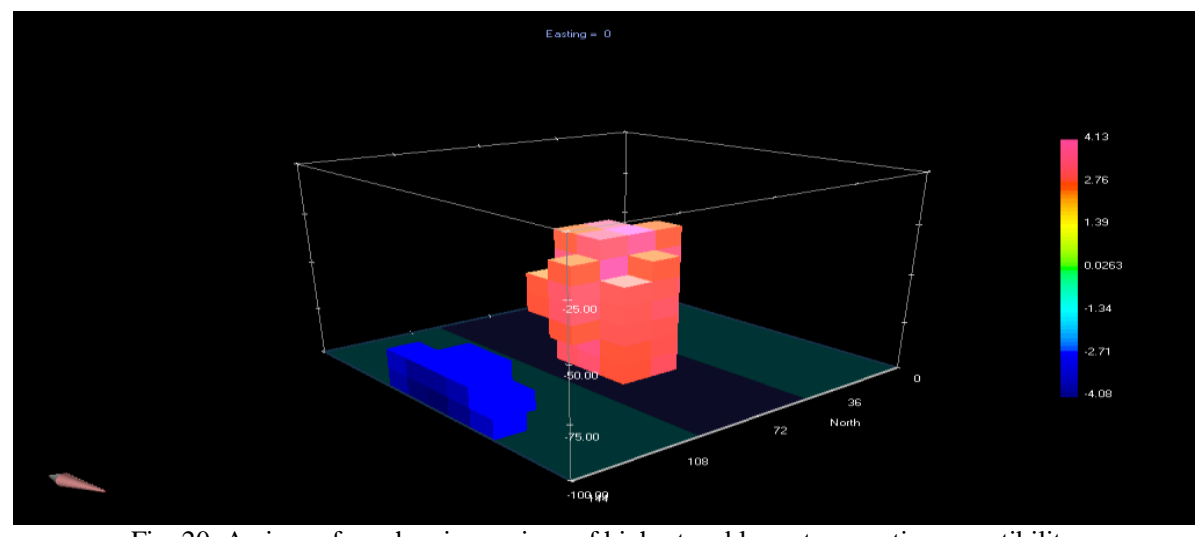

Fig. 20: An isosurface showing regions of highest and lowest magnetic susceptibility 


\subsection{Resistivity survey result}

Geoelectric data can be presented in many ways. There is one conventional plotting scheme for soundings, while plotting of profiles depends upon the survey configuration. The conductivities of mineral rocks were investigated and five Vertical Electrical Soundings (VES) were taken randomly on the study area. The resulting plots (Sounding curves) are shown in fig. $21-25$.
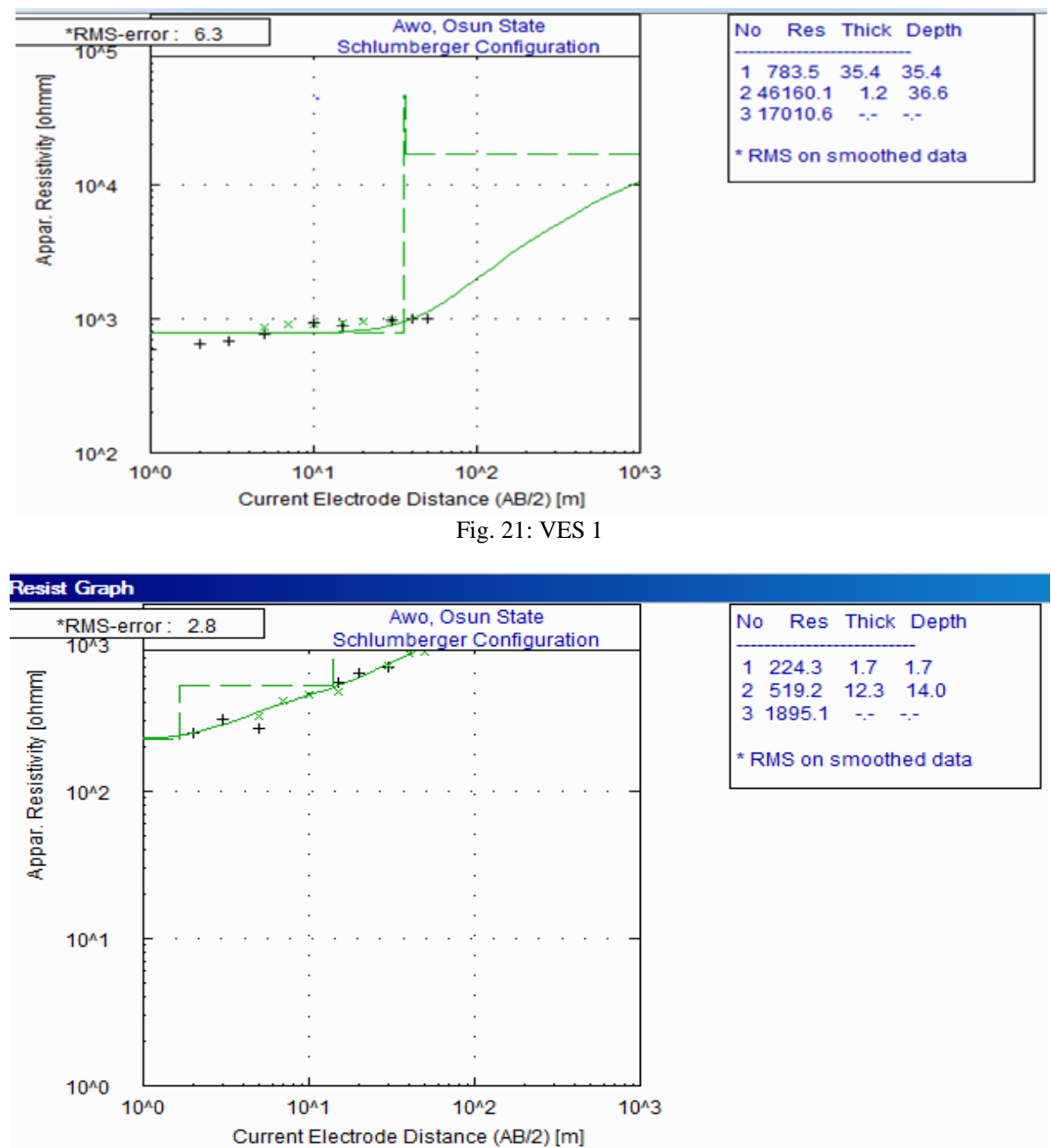

Fig. 22: VES 2
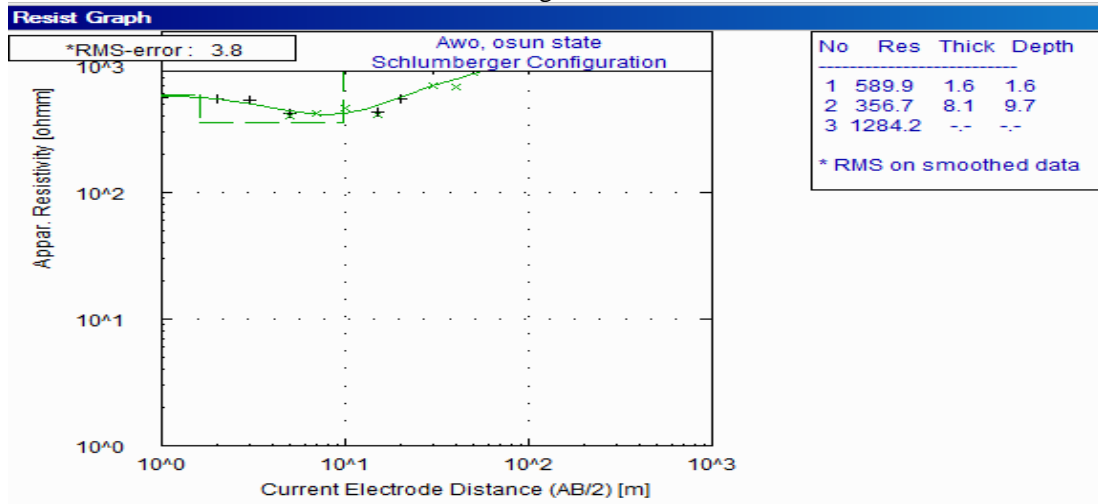

Fig. 23: VES 3 


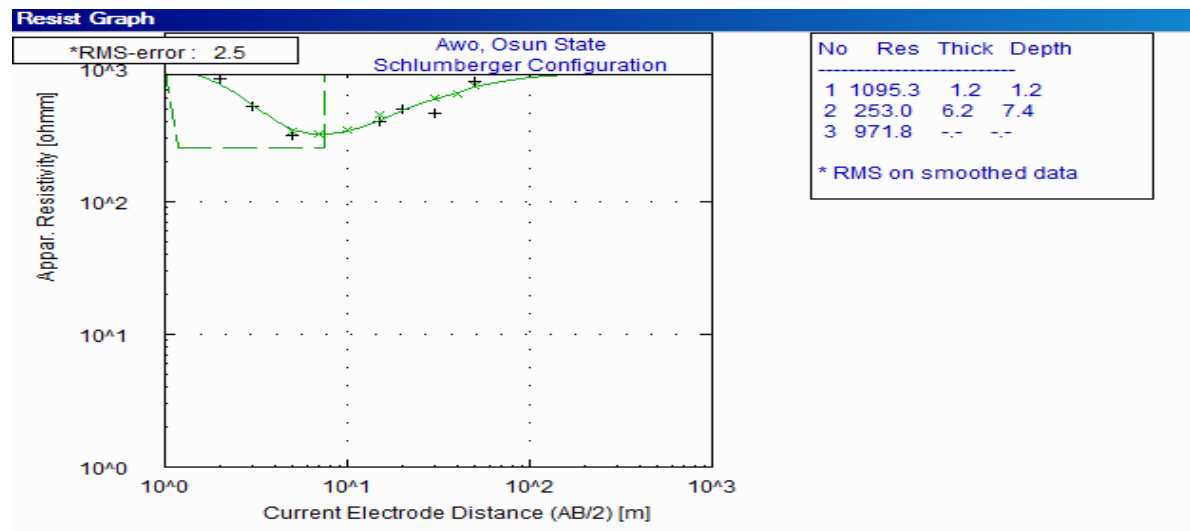

Fig. 24: VES 4

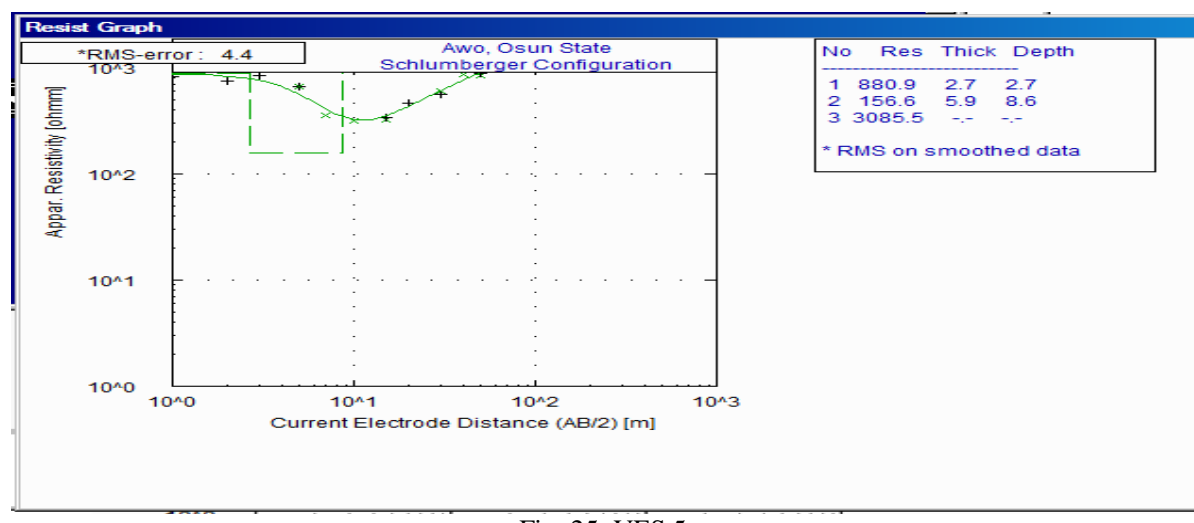

Fig. 25: VES 5

The table below summarizes the sounding curves (fig. 21 to 25) and gives possible rocks in each layer of the Vertical Electrical Soundings (VESs).

\subsection{Discussion}

The magnetic field intensities on each of the profiles are shown in fig. 2 to 11 . A visual inspection of the coloured map (fig. 12) shows that the contour lines of the North-Western part of the map are widely spaced indicating that the depth to magnetic basement in these areas are relatively large. Whereas, from the center to the South - Western part of the map, the contour lines are closely spaced indicating that the depth to the basement are shallow in these areas. The closely spaced, linear sub parallel orientation of contours from the center of the map towards the West suggests the possibility of faults or local fractured zones passing through these areas [9].

On the basis of the variation in magnetic intensity across the study area, there was a general increase in magnetic intensity from the center towards the South - Western region and there was a pronounced negative magnetic intensity at the North - Western region of the magnetic map. This variation is a function of the lithology of the basement complex. The magnetic signature obtained for the total component relative magnetic intensity plot along the traverses showed considerable varying amplitude from a minimum negative peak value of about $-80.61 \mathrm{nT}$ at a distance of about $80 \mathrm{~m}$ from the first station to a maximum positive peak value of about $89.68 \mathrm{nT}$ at a distance of about $50 \mathrm{~m}$ from the first station.

The inversion shows regions of high magnetic susceptibility indicating the presence of metallic mineral such as Columbite and Tantalite while regions of low magnetic susceptibility also indicating the presence of rocks such as Sandstone, Quartz and Calcite. The possible locations and depths of minerals of highest and lowest magnetic susceptibility are shown in fig. 20. Blank regions show intermediate magnetic susceptibility and it indicates the presence of rocks such as Beryl, Garnets, Mica and Tourmaline.

In VES 1 and 2 (fig. 21 and 22), the complex basements are very close to the surface of the earth and the resistivity of rocks increase with depth. In VES $3-5$ (fig. $23-25$ ), the resistivities of rocks decrease with depth and at a certain depth the resistivity start to increase with depth. The resistivity values of rocks and minerals revealed by VES 1 to 5 were compared with published (standard) magnetic susceptibility of rocks and minerals. We deduced that VES 1 (West of the study area) is underlain with rocks of high resistivity and low magnetic susceptibility, VES 2 and 3 (East of the 
study area) shows rocks with low resistivity and high magnetic susceptibility, VES 4(taken across the study area) and VES 5(South of the study area) reveal rocks with relatively low resistivity and relatively high magnetic susceptibility. Magnetite is a black magnetic mineral consisting of iron oxide and it is highly conductive. It is present in rocks in VES 2 to 5 and this shows that there are some magnetic rocks or minerals in the areas where the VES were taken. Rocks such as Tantalite, Beryl, Coltan, Mica and Gemstones are suspected to be in the study area.

\begin{tabular}{|c|c|c|c|c|c|c|}
\hline VES & LAYERS & $\begin{array}{l}\text { RESISTIVITY } \\
\text { (ohm-meter) }\end{array}$ & $\begin{array}{l}\text { DEPTH } \\
\text { (meter) }\end{array}$ & $\begin{array}{l}\text { THICKNESS } \\
\text { (meter) }\end{array}$ & POSSIBLE ROCKS & CURVE TYPES \\
\hline \multirow{3}{*}{1} & 1 & 781.2 & 35.5 & 35.5 & Sandstone, Clay & \multirow{4}{*}{ A - Type } \\
\hline & 2 & 46179.3 & 36.5 & 1.2 & Quartzite, Marble, Slate & \\
\hline & 3 & 17420.8 & & & $\begin{array}{c}\text { Quartzite, Anthracite, } \\
\text { Slate }\end{array}$ & \\
\hline \multirow{3}{*}{2} & 1 & 224.3 & 1.7 & 1.7 & Magnetite ore & \\
\hline & 2 & 519.2 & 14.0 & 12.3 & Magnetite ore & \multirow[b]{2}{*}{ A - Type } \\
\hline & 3 & 1895.1 & & & $\begin{array}{c}\text { Sandstone, Basalt, } \\
\text { Gabbro }\end{array}$ & \\
\hline \multirow{3}{*}{3} & 1 & 589.9 & 1.6 & 1.6 & Magnetite ore & \multirow{4}{*}{ H - Туре } \\
\hline & 2 & 356.7 & 9.7 & 8.1 & Magnetite ore & \\
\hline & 3 & 1284.2 & & & $\begin{array}{c}\text { Sandstone, Schist, } \\
\text { Basalt }\end{array}$ & \\
\hline \multirow[b]{2}{*}{4} & 1 & 1095.3 & 1.2 & 1.2 & Sandstone, Shale, Schist & \\
\hline & 2 & 253.0 & 6.2 & 7.4 & Magnetite ore & \multirow{3}{*}{ H - Type } \\
\hline \multirow{4}{*}{5} & 3 & 971.8 & & & Sandstone, Schist, Shale & \\
\hline & 1 & 880.9 & 2.7 & 2.7 & Sandstone, Shale, Schist & \\
\hline & 2 & 156.6 & 5.6 & 8.6 & Magnetite ore & \multirow[b]{2}{*}{ H - Type } \\
\hline & 3 & 3085.5 & & & $\begin{array}{c}\text { Sandstone, Schists, } \\
\text { Gabbros }\end{array}$ & \\
\hline
\end{tabular}

\section{Conclusion}

Geomagnetic and Geoelectric methods have been used to investigate the location and depth of magnetic rocks in the study area. The results of the two geophysical methods were in agreement and the following conclusions could be made.

There are rocks and minerals with high magnetic susceptibility and high conductivity values from the center to the south western region of the study area, and mineral rocks with low magnetic susceptibility and low conductivity values at the north western region of the study area. This conclusion affirms the earlier conclusion by [25] that the same minerals are responsible for both the conductivity and susceptibility of rocks.

The possible rocks in region of high magnetic susceptibility and high conductivity are Coltan and Tantalite while rocks in region with low magnetic susceptibility and low conductivity are Sandstone, Quartz, Graphite, Feldspar and Calcite. More than $50 \%$ of the volume has an intermediate magnetic susceptibility values (figure 20), indicating that the region is predominantly a pegmatite vein and haboured rocks such as Beryl, Garnets, Mica and Tourmaline in massive and disseminated quantities.

\section{Acknowledgements}

The author acknowledge Mr. John Ogunmola for providing some useful literatures and software for this study, and Mr. M. A. Fakunle for his assistance on the research field

\section{References}

[1] Ahzegbobor, P. A. (2010): Acquisition geometry and inversion of 3D geoelectrical resistivity imaging data for environmental and engineering investigations. $\mathrm{PhD}$ thesis, Covenant University, Nigeria.

[2] Al-chalabi, M., (1971): Some studies relating to non-uniqueness in the gravity and magnetic inverse problems. Geophysics $36,835-854$.

[3] Ajayi, T.R., (1981): On the geochemistry and origin of the Amphibolites in ife - ilesha area S.W. Nigeria. J. Min. Geol., 17: 179-196.

[4] Blakely, R. J., (1995): Potential theory in gravity and magnetic applications: Cambridge University Press. 
[5] Butler, D. K., (2005): Near Surface Geophysics textbook

[6] Constable, S. C., Parker, R.L. and Constable, C. G. (1987): Occam inversion: A practical algorithm for generating smooth models from electromagnetic sounding data. Geophysics, 54 pp. 289-300

[7] Folami, S.L., (1980): Interpretation of aeromagnetic anomalies in Iwaraja area, South WesternNigeria. J Mm, Geol., volume 28(2), pp 393397.

[8] Ishola, K.S., Adeoti, L., Obianeri, A. (2012): Interpretation of the historic site, Agorin in Badagry, Southwestern Nigeria using geophysical methods. Ozean Journal of Applied Sciences 5(1), pp 85 - 99.

[9] Kayode, J.S., (2006): Ground magnetic study of Jeda-Iloko area, South-Western Nigeria and its geological implications. M.Tech. thesis Fed. Univ. of Tech. Akure, Nigeria.

[10] Kayode J. S. and Adelusi A.O. (2010): Ground Magnetic Data Interpretation of Ijebu-Jesa Area, Southwestern Nigeria, Using Total Component Research Journal of Applied Sciences, Engineering and Technology 2(8): 703-709.

[11] Keller G.V. and Frischknecht F.C. (1966): Electrical methods in geophysical prospecting. Pergamon Press Inc., Oxford.

[12] Koefoed O. (1979): Geosounding Principles 1; Resistivity sounding measurements. Elsevier Science Publishing Company, Amsterdam.

[13] Lelievre, P. G. and Oldenburg, D. W., (2006): Magnetic forward modelling and inversion for high susceptibility. Geophysical Journal International, vol. 166, pp76-90.

[14] Li, Y., and D. W. Oldenburg (1996): 3-D inversion of magnetic data: Geophysics, 61, 394-408.

[15] Li, Y., and D. W. Oldenburg (2003): Fast inversion of large-scale magnetic data using wavelet transforms and a logarithmic barrier method: Geophysical Journal International, 152, 251-265.

[16] Li, Y. and Oldenburg, D. W. (2006): Magnetic forward modeling and inversion for high susceptibility, Geophysical Journal International, vol. 166, pp 76-90.

[17] McGillevry, P.R. (2005): Forward modelling and inversion of de resistivity and mmr data using UBC, unpublished PhD. thesis.

[18] National Geophysical Data Center's calculator, www.ngdc.noaa.gov/

[19] Odunaike, R.K., Ijeoma, G. C., Edigbe, R.O., Babatope A. H. (2009) Oil sands exploration in ijebu-Imushin using magnetic and electrical resistivity methods.

[20] Okunlola, O. A., Adeigbe, O. C. and Oluwatoke, O. O. (2009): Compositional and petrogenetic features of schistose rocks of Ibadan area, southwestern Nigeria. Earth Sciences Research Journals, vol. 13 (2), pp. 29-43.

[21] Olusegun, O., Kehinde-Phillips and F.T. Gerd, (1995): The mineralogy and geochemistry of the weathering profiles over amphibolite, anthophillite and talcschists in Ilesa schist belt, southwestern Nigeria. J. Min. Geol., 31(1): 53-62. \#

[22] Oni, R., and Ebun, B., (1969): Measurement and Interpretation of magnetic anomaly components in Low latitude, Journal of geophysical Research, Vol. 74, pp 17, pp 4233- 4245.

[23] Parasnis, D.S. (1997): Principles of Applied Geophysics. 5th ed. London: Chapman and Hall.

[24] Rahaman, M.A., (1976): Review of the basement geology of southwestern Nigeria In: Kogbe, C.A. (Ed); Geology of Nigeria. Elizabethan publishing co., Lagos pp, 41-58.

[25] Roger, S. (2008): Magnetic Susceptibility as a Tool for Investigating Igneous Rocks, experience from IODP Expedition 304.

[26] Shearer, S., and Y. Li, 2004, 3D Inversion of magnetic total gradient data in the presence of remanent magnetization: 74th Annual Meeting, SEG, Technical Program Expanded Abstracts, 23, 774-777.

[27] Telford, W.M., Geldart, L.P. and Sheriff, R.E. (1990): Applied geophysics 3rd Edition, Cambridge University Press, Cambridge, pp 68-110. 